\title{
Restructuring Serials Management to Generate New Resources and Services-With Commentaries on Restructurings at Three Institutions
}

\section{Charles A. Schwartz}

\begin{abstract}
Restructuring serials management along access-versus-ownership lines does not solve the serials crisis, but it does alleviate inflationary pressures and has other significant outcomes. The main economic outcome is the cancellation of low-use, high-cost-per-use titles to create a large pool of savings for reinvestment in new resources and services. The main service outcome is a fully subsidized, unmediated document delivery system-for a fraction of the cost savings. The main political outcome is a resolution of the "tragedy of the commons" phenomenon, which tends to dominate library-faculty relations based on conventional serials management.
\end{abstract}

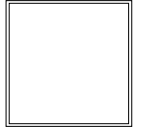

eople can define problems in ways that overwhelm their ability to do anything about them. Indeed, the serials crisis generally has been thought to be a systems-level economic problem having no workable solution. However, it is primarily-on the local (real-world) level—a political matter akin to the "tragedy of the commons" phenomenon which can be alleviated with significant other outcomes. The "tragedy" is that the faculty have no reason to cooperate with conventional serial cancellation projects, which amount to a perpetual budget-slashing act that leaves all stakeholder groups progressively worse off. Figuring out a more rational model in which all stakeholder groups come out ahead, economically and politically, is the essential problem.
Variations of a new service model based on the restructuring of serials management along access-versus-ownership lines have been developed by a small number of academic libraries. The key factor is a fairly comprehensive serials cancellation project to generate a large pool of savings for reinvestment in new resources and services. The principal added service-the linchpin of the model-is a fully subsidized, unmediated document delivery system. Interest in this model has grown on the Internet and at conferences, but accounts of collections actually being restructured are rare. ${ }^{1}$ This article seeks to help fill that gap in the literature by providing a case study of the model at the University of MassachusettsBoston (UM-B) and by presenting commentaries from library managers at three 


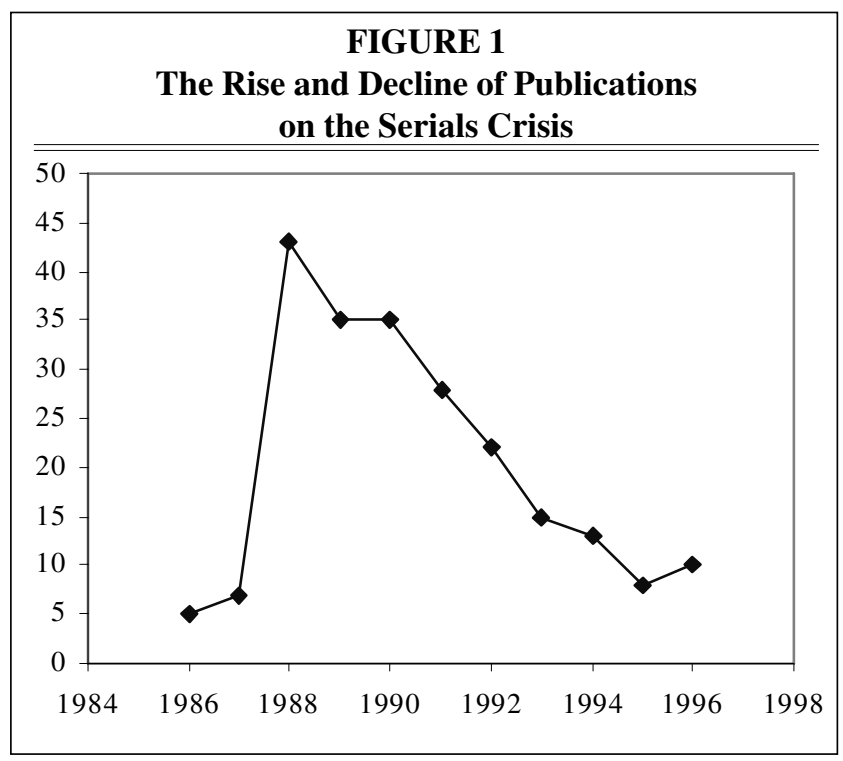

Literature Overview

In the main, the literature on the serials crisis consists of two types of studies. One type focuses on the oligopolistic structure of this publication market (in which a few producers dominate the scale of prices). None of those systems-level studies provides any real solution for making serials management more effective. ${ }^{2}$ Instead, they have called over the years for a variety of grand reforms, including a general freeze on serial budgets, a fed-

other institutions on their respective experiences. Restructuring serials management at UM-B in 1996 was a three-part plan:

- relying on faculty decisions, canceling hundreds of low-use, high-cost-peruse (or other peripheral) serials for cost savings in the range of a quarter of a million dollars;

- reinvesting about 20 percent of the savings in an UnCover system that enables authorized users to order, from their home or office, any article from a serial not in the library's collection and to receive it, free of charge, usually within twenty-four hours;

- reinvesting another 10 percent (or so) of savings in new serials and networked resources.

This study is developed in six parts. The first part is an overview of the literature. The second contrasts serial cancellation decision models. The third describes UM-B's economic methods and outcomes. The fourth focuses on the resolution of the "tragedy of the commons" phenomenon. The fifth provides a brief summary of the model's strengths and limitations. And the last part presents the commentaries. eral subsidy for the scholarly communication system, a letter campaign against "greedy" publishers, a steep hike in photocopy charges to force the demand for private journal subscriptions, and the abolition of the academic rewards system underlying publication proliferation..$^{3-8}$

The bulk of the literature-more than 200 publications-is narrow and descriptive, detailing inflation patterns in subject fields or announcing results of serial cancellation projects. Such reports tend to reiterate, in a line or two, the same systems-level proposals for some restructuring of the serials market. The sharp decline of publications on the serials crisis this decade suggests that our profession has tired of the usual accounts-and perhaps that it has acquiesced to spiraling inflation (a specter once termed the "doomsday library machine"). Figure 1 shows the rise and decline of publications on the serials crisis between 1986 and 1996.

\section{Decision Models}

No serial cancellation decision model fits all parts of the collection or applies to both restructuring projects and normal times. 
Cost-per-use analysis is superior to the conventional prices $\mathcal{E}$ quotas method for a comprehensive cancellation project involving the sciences. As discussed below, a variant of cost-per-use analysis may be more expedient to cope with inflation in the sciences when restructuring is not in process, whereas the prices \& quotas method seems inevitable for the social sciences and humanities.

Prices \& quotas simply aims to expedite a cancellation project by targeting the most expensive titles:

Dollar quotas force bibliographers and faculty to factor the cost of a journal into the overall benefit that will be derived from it, to realize that the wisest choice may sometimes be to cut the 'best' title on the list if it is by far the most expensive. It leads them, in short, to find a few titles that will go a long ways toward getting it over with. ${ }^{9}$

An opposing model-the focus of this study-is cost-per-use analysis. Although the figures are easily computed with spreadsheets, the usage (reshelving) study is laborious and takes two semesters to accumulate reliable data. Nonetheless, such analysis produces both interesting micro-level findings (on a title-by-title basis) and persuasive macrolevel indicators of the benefits to accrue from restructuring the collection.

Cost-per-use analysis involves dual criteria: low use coupled with high cost per use (cost per use being the ratio of subscription price to usage). ${ }^{10}$ "High" cost per use is an estimated threshold, or tipping point, at which ownership becomes much more expensive than access, whereas "low" use is a somewhat arbitrary range (usually zero to five). In actual practice, this kind of analysis is more varied and looser than the dual framework. A survey (by this author) of fiftythree academic libraries that engage in access-versus-ownership decision-mak- ing found a widespread tendency to uncouple the criteria, putting little emphasis on low use while focusing on high cost per use. ${ }^{11}$ Thus, very expensive serials are tracked and, when cancellations become necessary to offset inflation, usage figures somewhat above the low-use line are disregarded. Of course, to treat the low-use criterion as inviolable would impede budget balancing. Yet, focusing on the most expensive titles has the ironic tendency of making this approach quite similar to the prices \& quotas method it was intended to replace.

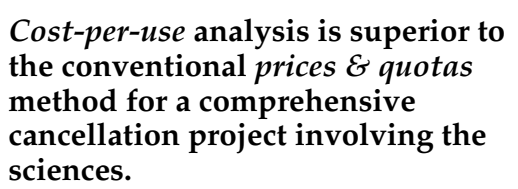

When the purpose of a cancellation project shifts from incremental budget cuts to a comprehensive restructuring of the collection, the criteria of low use and high cost per use must be accorded fairly equal status for the analysis to have a coherent structure. Roughly 80 percent of science serials have a cost per use in the hundreds of dollars, so it would be economically rational to cancel the greater part of the science collection. ${ }^{12}$ For a balanced outcome, the low-use criterion comes into play-and that turns the analysis around, with about 20 percent of the science collection then being targeted.

Although the dual criteria make the analysis coherent, a dilemma arises for the library. On the one hand, coherence would last only as long as the low-use criterion was treated as a metadecision that no serials over that boundary line would be targeted. Coherence would thus rob the library of its title-by-title discretion and flexibility. On the other hand, if the low-use criterion was relaxed by the library's targeting some titles that were over the boundary line, there would be no logical stopping point because the great 


\begin{tabular}{|c|c|c|c|}
\hline \multicolumn{4}{|c|}{$\begin{array}{l}\text { TABLE } 1 \\
\text { Access-versus-Ownership for UM-B, at a Glance } \\
\end{array}$} \\
\hline & $\begin{array}{l}\text { Average } \\
\text { Number Uses }\end{array}$ & $\begin{array}{c}\text { Average } \\
\text { Cost per Use }\end{array}$ & $\begin{array}{l}\text { Average } \\
\text { UnCover }\end{array}$ \\
\hline All science serials & 19 & $\$ 65$ & \\
\hline \multicolumn{4}{|l|}{ Range of use } \\
\hline 296 low & zero to 5 & $\$ 537$ & $\$ 13$ \\
\hline Subset of 255 marginal & zero to 3 & $\$ 605$ & \\
\hline \multicolumn{4}{|c|}{$\begin{array}{l}\text { If all } 296 \text { low-use, high-cost-per-use serials had been shifted from ownership } \\
\text { to access the previous year, total document delivery charges would have been } \\
\text { about } \$ 3,000 \text {, less than two percent of total costs of } \$ 215,000 \text {. }\end{array}$} \\
\hline
\end{tabular}

average for lowuse, high-cost-peruse titles (\$537) or the subset of extremely low-use titles (\$605). ${ }^{13}$ With nearly 300 titles in this pool of potential cost savings, the library could well afford to let the academic departments pick and

majority of science serials conceivably could be cut on strictly economic grounds. Thus, some mechanism is necessary to keep cost-per-use analysis out of the kinds of library-faculty frays that arise with the prices \& quotas method. For a large cancellation project involving scores of potentially distrustful stakeholder groups on campus, coherence is no mere nicety.

The way to resolve this dilemma of decision-making flexibility versus decisionmodel coherence is for the library to delegate micromanagement of the title-by-title decisions to the academic departments. They can put varying emphases on the different criteria and consider the whole process to be quite reasonable. The library's economic interests are secure because the overall cost savings will be substantial regardless of particular title decisions.

\section{UM-B's Economic Methods and Outcomes}

UM-B's resolve to restructure serials management began with a single striking statistic. As shown in table 1, the provision of document delivery for every low-use, high-cost-per-use serial in the sciences would cost about two percent of their total subscription costs-a savings of well over $\$ 200,000$ a year. Another telling statistic in table 1 shows that a large cancellation project was bound to generate substantial savings, given the ninefold difference between the average cost-per-use of the science collection as a whole (\$65) and the choose within the pool.

\section{“Good Enough" Aggregate Projections ${ }^{14}$}

Projected cancellations at UM-B ranged from $\$ 200,000$ to $\$ 225,000$ for the sciences alone. Any such outcome was "good enough" because the share of savings to be reinvested in document delivery (estimated at $\$ 40,000$ a year, including the $\$ 10,000$ UnCover fee for a customized system) varied only five points (from 17 to $20 \%$ ). The actual cancellation total (including nonscience fields) was $\$ 227,000$. With the additional reinvestments (115 new serials and some databases), the savings amounted to three-quarters of former ownership costs and offset future inflationary pressures by a third.

On that scale, the somewhat arbitrary values that were selected to define the low-use criterion and the access-versusownership threshold hardly mattered. UM-B had set the low-use criterion at five but discovered that 86 percent of low-use serials were in the zero-to-three range. As for the access-versus-ownership threshold value (\$18), it could have been doubled without lowering the share of cost savings by more than two percentage points.

\section{The Relative Insignificance of the Price Factor in the Sciences}

Subscription price was a relatively insignificant decision factor compared to cost per use in the sciences. Table 2, based on five departments that accounted for 70 


\begin{tabular}{|c|c|c|c|c|c|c|c|c|}
\hline \multicolumn{9}{|c|}{$\begin{array}{l}\text { TABLE } 2 \\
\text { Serial Price as an Insignificant Factor Relative to Cost-per-Use }\end{array}$} \\
\hline & \multicolumn{2}{|c|}{ Average Price } & \multirow[b]{2}{*}{$\begin{array}{l}\text { Standard } \\
\text { Deviation }\end{array}$} & \multirow[b]{2}{*}{$\begin{array}{c}\text { Extreme } \\
\text { Price }\end{array}$} & (5) & \multirow[b]{2}{*}{$\begin{array}{l}\text { Whammies } \\
\text { * Cut }\end{array}$} & \multicolumn{2}{|c|}{ Average CPU } \\
\hline & $\begin{array}{l}\text { Low Use, } \\
\text { High C.P.U. }\end{array}$ & $\begin{array}{c}\text { Per } \\
\text { Field } \\
\end{array}$ & & & $\begin{array}{l}\text { Double } \\
\text { Whammies* }\end{array}$ & & $\begin{array}{c}\text { Per } \\
\text { Field } \\
\end{array}$ & $\begin{array}{c}\text { Low-Use } \\
\text { Titles } \\
\end{array}$ \\
\hline Biology & $\$ 531$ & $\$ 669$ & $\$ 868$ & $\$ 1,537$ & 8 & 6 & $\$ 35$ & $\$ 261$ \\
\hline Chemistry & 871 & 1199 & 1402 & 2601 & 2 & 1 & 106 & 686 \\
\hline $\begin{array}{l}\text { Environmental } \\
\text { sciences }\end{array}$ & 593 & 672 & 748 & 1420 & 3 & 1 & 52 & 465 \\
\hline $\begin{array}{l}\text { Mathematics } \\
\text { \& computer } \\
\text { science }\end{array}$ & er & 514 & 536 & 1050 & 16 & 6 & 143 & 548 \\
\hline Physics & 1376 & 1489 & 2126 & 3615 & 2 & 1 & 180 & 876 \\
\hline Weighted avgs & $\$ 710$ & $\$ 827$ & $\$ 1026$ & $\$ 1853$ & 31 & 15 & $\$ 90$ & $\$ 504$ \\
\hline
\end{tabular}

percent of all cost savings, outlines the main reasons. As shown in columns 1 and 2 , the average price of low-use, high-costper-use titles was actually lower than the average price in four of the five fields. Next, consider the extreme case of double whammy serials, those of very high cost and low use. The "extreme price" (column 4) threshold begins at one standard deviation above the average price, with most double whammies tripling the average price (due to big standard deviations). Of those thirty-one titles, the science departments decided to keep half (columns 5 and 6).

Because any librarian with a price \& quotas perspective would have targeted all thirty-one, the case of the double whammies might seem a worst-case scenario of academic departments' broad discretion. Yet, the sixteen retained double whammies amounted to only $\$ 24,000$ - an amount that would have increased total project savings just 10 percent. With those five science departments' cutting $\$ 170,000$ overall, making a fuss over some titles they considered indispensable would have been impolitic.

\section{Old-Style Review in the Social Sciences and Humanities}

Without usage data for the social sciences and humanities, UM-B's serials review was more conventional. In proportional terms, the results were "good enough" for the universitywide process to be judged equitable: Cuts in the social sciences and humanities amounted to 25 percent of those budgets, as opposed to an overall rate of 34 percent in the sciences. In absolute terms, of course, the results were disparate. The social science and humanities departments cut almost twice as many titles (313, as opposed to 188 in the sciences) but represented only a fifth $(\$ 52,000)$ of aggregate savings. The different price structures were most reflected in extreme price serials (those at least one standard deviation above the average price in a field). Social science and humanities departments cut five times as many such titles (73 of 200) as did science departments (15 of 31) but generated barely the same savings $(\$ 32,500$, as opposed $\$ 30,000$ in the sciences). However, extreme price title cuts accounted for twothirds of the overall contribution of the social sciences and humanities to the project, making the process politically equitable. 


\section{Resolving the "Tragedy of the Commons"}

The "tragedy" pertains to situations in which a limited resource (or public good) is shared by a number of users who, although they must act on a basis of fairness or equity to conserve that resource, have no immediate incentive to do so. Self-interested behavior eventually depletes the resource, leaving everybody worse off. The textbook example of a meadow shared by too many herdsmen may be intuitively familiar:

Each economically rational herdsman [academic department] seeks to get the most benefit possible of the common pasture [serials budget] by maintaining a sizeable herd [serials list]. A day of reckoning comes when the commons starts to be depleted. In agrarian society, cows die off [on campus, serials are cut]. ${ }^{15}$

Conventional serials management, economically and politically, is quite conservative. A continuous series of incremental cancellation projects every few years amounts to a model of "muddling through." With the new service model, however, the library's role changes from micromanaging serial cuts to orchestrating what amounts to a paradigm shift for the faculty. This new role depends on all academic departments being assured that the library will exercise its responsibility of enforcing the equity of the cancellation project in order to avoid the "tragedy of the commons" phenomenon.

\section{Restructuring Seen as an Intelligent Move}

An intelligent move is often thought to require clear-cut outcomes. In a comprehensive serials review, however, particular outcomes (titles cut, especially double whammies) are far less important than the character of the process itself. As we have seen, access-versus-ownership decision factors are neither precise nor prescrip- tive. Although the intelligence of restructuring is as broad and concrete as the idea of doing things in cost-effective ways, it is primarily local and symbolic, based on the library's decision to rely on the discretion of the faculty. That initial decision goes a long way toward resolving both the "tragedy of the commons" phenomenon and the dilemma of a flexible-versus-coherent decision process. So much depends on who is taking the initiative! If the faculty is put in the usual position of defending their fields from the library's targets, the restructuring will not appear to be an inherently intelligent move. As a case in point, consider the argument for the library to target all cuts: "The fear some faculty have of what those idiots in the library might do if left to their own devices can be our most powerful source of leverage in motivating faculty participation."16

With regard to numbers and statistics, the intelligence of restructuring is best conveyed with vivid information that is local, concrete, and easy to remember (see figure 2). On a general level, the kind of information shown in tables 1 and 2 -the

\section{The social science and humanities departments cut almost twice as many titles (313, as opposed to 188 in the sciences) but represented only a fifth $(\$ 52,000)$ of aggregate savings.}

extreme differential between high and average costs per use, together with the comparison of overall access and ownership budgets-should be prominent in campus meetings on the new service model. Statistics on inflation, by contrast, are relatively pallid and point in the wrong direction-at the problem rather than the solution.

\section{Top-down Deliberation and Bottom-up Review}

Although it is crucial for the library to engage the powerful science departments from the start, campus politics must ad- 


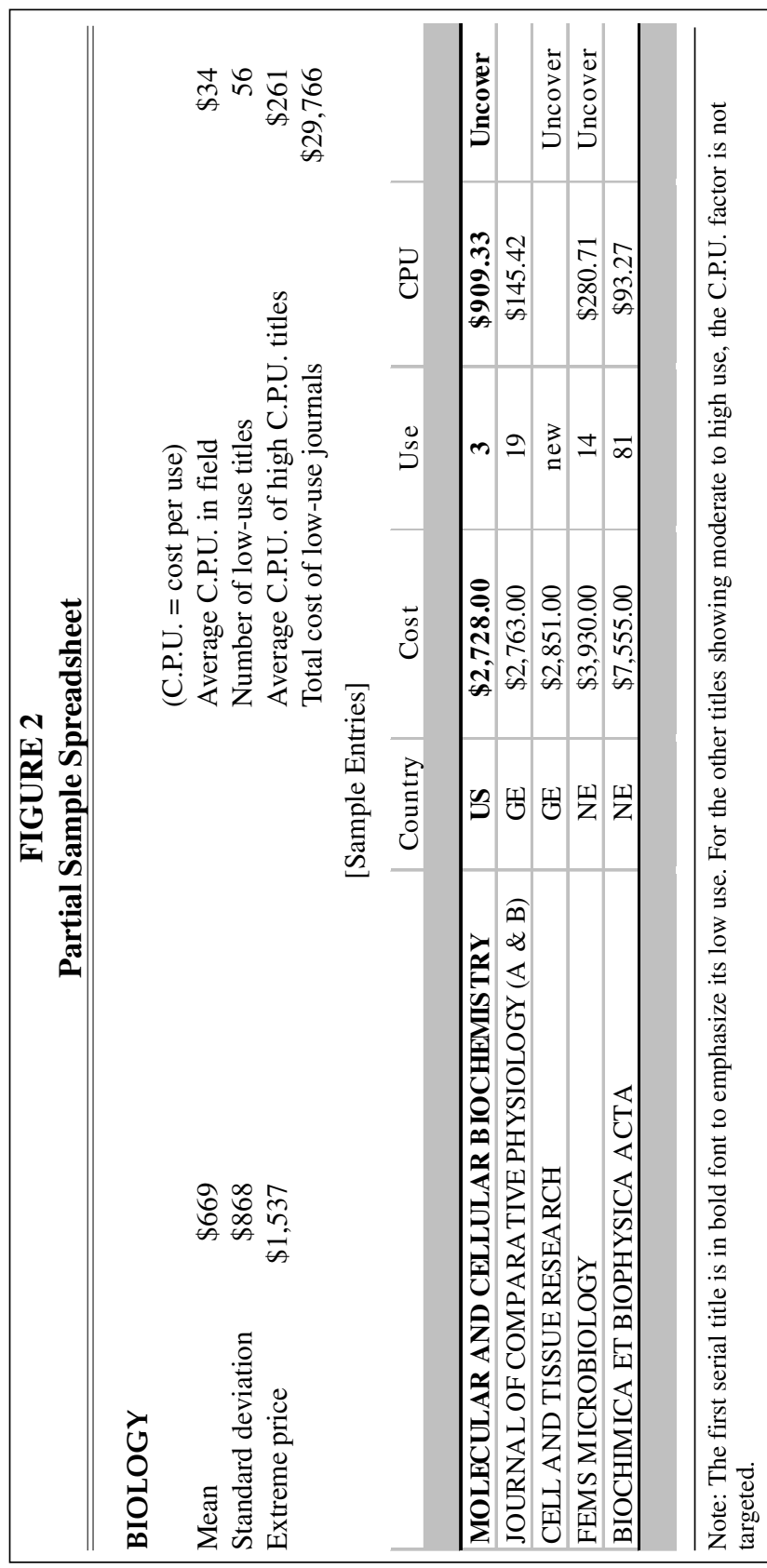

meetings with the academic department chairs of a given college or division. A group setting reinforces the chairs' interdependence for the achievement of equitable outcomes in the serials review (i.e., it brings to the fore the potential problem of "free riders," who would not make their fair share of cuts).

Bottom-up review, coming after the departmental access-versusownership decisions, is a university-wide "safety check" with the distribution of two lists of all cuts, one for the sciences and the other for the social sciences and humanities. In this review, the library adjusts cross-departmental or interdisciplinary needs. By releasing chairs of the concern that they might cancel a title of importance to another department, it both expedites the decision process and enlarges the number of cuts. It also frees the chairs from being personally involved in a dispute with a colleague over some title; otherwise, chairs might reverse decisions, causing savings-and process equities-to unravel.

Another kind of "safety check" is UnCover's monthly reports on all se-

dress the concerns of all stakeholder groups. Top-down deliberation begins by enlisting the support of the provost, proceeds to lunches with the academic deans individually, and then shifts to group rial requests and individual requestors. The data would enable the library to make reverse decisions, from access to ownership, for serials in high demand. However, in UM-B's experience, 70 percent of document deliv- 
eries have involved only one article from a particular serial, and less than 5 percent of serials involve more than four document deliveries. As for overuse of the service, we have asked only two people out of hundreds to "flag" more citations (for interlibrary loan) and not to "mark" so many (for document delivery). ${ }^{17}$ In UM$B$ 's safety check review as a whole, 10 percent of title cuts (50) were appealed and about one in seven reinstated by the project head, affecting less than 3 percent of total savings. This review had a largely symbolic role: The faculty seemed less interested in getting their way than in a formal mechanism for having a say.

\section{Concluding Remarks}

The new service model for serials access has three main strengths: It provides for informed planning, improved relations with the faculty, and new resources and services at a fraction of cost savings. The model's limitations also are summarized here. A final point of discussion is the speculative issue of why more libraries have not adopted this model.

\section{Model Strengths}

With respect to informed planning, the library can determine quite early the economic prospects of a fairly comprehensive serials cancellation project, the key factor being the large differential between average cost per use and high cost per use for hundreds of low-use titles. ${ }^{18}$ Improved relations with the faculty will accrue on several fronts. The library's delegation of access-versus-ownership decisions to the faculty will make the cancellation project appear to be an inherently intelligent move. In addition, the faculty no longer will be in a defensive situation, which is the crux of disputes; and they will take the serials review quite seriously, having been given both interesting data on the use of the collection and the quid quo pro of new subscriptions and even databases along with the document delivery system. At the same time, the cancellation project will be an instrument of confidence building in the ability and resolve of the library to come to grips with a perennial financial and service problem.

\section{Model Limitations}

The new service model is not a resolution of the serials crisis; prolongation of serials inflation will require recurring cuts over the years. Also, because cost-per-use analysis is not suitable for the social sciences and humanities, the approach taken by many of the fifty-three surveyed libraries of doing usage counts for expensive titles in those fields looks to be the only feasible course. A third limitation of the service model is that fax delivery does not work for articles with images. Especially in the biological sciences, the library should have an additional, surface-mail document delivery service (e.g., the British Library Document Supply Centre).

A few aspects of UM-B's experience with the document delivery service warrant attention. The serials it owns, and articles costing more than $\$ 30$, are blocked from the ordering process. All of the academic departments that rely on the service were "early adopters" - that is, they began to use it within a few weeks of its availability-whereas this technology has not spread to some other departments even after a year of publicity. An unexpected finding was that over 90 percent of deliveries go to home or office fax machines (i.e., this system made for a "library without walls" rather than the library becoming a "print house").

\section{Why Have Not More Libraries Restruc- tured Serials Management?}

Does UM-B recommend the new service model? Not exactly; "recommend" is too strong a term. We suggest first a full understanding of all the work involved. The initial usage study is year long. Then, preparation of subject spreadsheets, even with vendor-supplied electronic data, may take someone working full-time a month to do. An updated holdings tape 
(for the document delivery system to block requests involving serials owned by the library) could be a stumbling block for some libraries. The essential point, however, is that serials management is not necessarily locked into "captive market" economics and "tragedy of the commons" politics.

The main reason more libraries have not restructured may be that they have not had the striking experience of seeing for their own budget and collection the kind of economic and service projections in tables 1 and 2. The untenable prospects for "serials management as usual" are well known, yet, on a workaday level, still distant and abstract. Unless the extreme difference between the access and the ownership models with regard to lowuse, high cost-per-use serials is based on local figures, it simply does not seem real enough to cause what amounts to a paradigm shift for the library and its stakeholder groups.

There is considerable evidence from the behavioral sciences that decision makers who are committed to particular programs tend to discount, ignore, or attack information that is at odds with such programs. ${ }^{19}$ Thus, faculty may disparage serial-usage data until that issue is defused by the library's delegation of title decisions to the academic departments. Collection managers may remain committed to the ownership model, even after their university administrations have mandated significant budget cuts. For that reason, a case study on restructuring probably will not change attitudes unless there is a predisposition to consider fun-

\section{The untenable prospects for "serials management as usual" are well known, yet, on a workaday level, still distant and abstract.}

damental change. A case study can be a cognitive map of the concepts, relations, and strategies of an organizational situation. However, a decision to restructure will likely require a preliminary analysis to see firsthand how prospective cost savings would generate new resources and services and alleviate inflationary pressures.

\section{Notes}

1. On restructuring a serials collection, see Charles A. Hamaker, "Re-Designing Serials Collections," Journal of Library Administration 20, no. 1 (1994): 37-47; David F. Kohl, "Revealing UnCover: Simple, Easy Article Delivery," Online (May/June 1995): 53-60; Jane Kleiner and Charles A. Hamaker, "Libraries 2000: Transforming Libraries Using Document Delivery, Needs Assessment, and Networked Resources," College and Research Libraries 58 (July 1997): 355-74.

2. On the nil prospects of a restructuring of the serials market, see Charles A. Schwartz, "Scholarly Communication as a Loosely Coupled System: Reassessing Prospects for Structural Reform," College E Research Libraries 55 (Mar. 1994): 101-17.

3. Association of Research Libraries, Report of the ARL Serials Prices Project (Washington, D.C.: ARL, 1989).

4. David W. Lewis, "Economics of the Scholarly Journal," College E Research Libraries 50 (Nov. 1989): 674-88.

5. H. Craig Petersen, "The Economics of Economics Journals: A Statistical Analysis of Pricing Practices by Publishers," College E Research Libraries 53 (Mar. 1992): 176-81.

6. Bruce Kingma and Philip Eppard, "Journal Price Escalation and the Market for Information: The Librarians' Solution," College E Research Libraries 53 (Nov. 1992): 523-35.

7. Anthony M. Cummings et al, University Libraries and Scholarly Communication (Washington, D.C.: ARL, 1992).

8. Michael Stoller, Robert Christopherson, and Michael Miranda, "The Economics of Professional Journal Pricing," College E Research Libraries 57 (Jan. 1996): 9-21.

9. Paul Metz, "Thirteen Steps to Avoiding Bad Luck in a Serials Cancellation Project," Journal of Academic Librarianship 18 (May 1992): 79. 
10. Dorothy Milne and Bill Tiffany, "A Cost-per-Use Method for Evaluating the Cost-Effectiveness of Serials: A Detailed Discussion of Methodology," Serials Review 17 (summer 1991): 719; Eleanor A. Gossen and Suzanne Irving, "Ownership versus Access and Low-Use Periodical Titles," Library Resources E Technical Services 39 (Jan. 1995): 43-52.

11. On December 12, 1995, I posted a request on two listserves (COLLDEV-L and PACS-L) for libraries that do cost-per-use analysis for access-versus-ownership decisions to identify themselves for a survey. From more than 60 responses, 53 completed the survey in spring 1996.

12. The economic rationality of canceling an entire science collection, making a complete shift to an access model, is not complete hyperbole; see Richard P. Widdicombe, "Eliminating All Journal Subscriptions Has Freed Our Customers to Seek the Information They Really Want and Need: The Result-More Access, Not Less," Science E Technology Libraries 14, no. 1 (1993): 3-13.

13. For case studies of cost-per-use analysis, see: Dorothy Milne and Bill Tiffany, "A Survey of the Cost-Effectiveness of Serials: A Cost-per-Use Method and Its Results," Serials Librarian 19, no. 3/4 (1991): 137-49; Sue Beardman, "The Cost-Effectiveness of Access versus Ownership: A Report on the Virtual Library Project at the University of Western Australia Library," Australian Library Review 13 (May 1996): 173-81; Anthony W. Ferguson and Kathleen Kehoe, "Access vs. Ownership: What Is Most Cost Effective in the Sciences?" Journal of Library Administration 19, no. 2 (1993): 89-99; Diane E. Reuss, "Changing Strategies for Information Delivery: Theory into Practice," Journal of Interlibrary Loan, Document Delivery E Information Supply 5, no. 4 (1995): 43-51; Tina E. Chrzastowski and Mary A. Anthes, "Seeking the 99\% Chemistry Library: Extending the Serial Collection through the Use of Decentralized Document Delivery," Library Acquisitions: Practice \& Theory 19 (summer 1995): 141-52; Gossen and Irving, "Ownership versus Access and Low-Use Periodical Titles."

14. The concept of "good enough" estimates or projections has a distinguished pedigree as the basis of Nobel prizewinner Herbert A. Simon's theory of the "satisficing" decision model. Herbert A. Simon, Reason in Human Affairs (Stanford, Calif.: Stanford Univ. Pr., 1983), 85.

15. Adapted from Garrett Hardin, "The Tragedy of the Commons," Science 162 (Dec. 13, 1968): $1,243-48$.

16. Metz, "Thirteen Steps to Avoiding Bad Luck in a Serials Collection Project," 77.

17. Conventional wisdom holds that free services to the typical user are devalued to the point of being abused-the "free rider" problem in the "tragedy of the commons." However, some recent research suggests that this problem is more theoretical than real, that users of free services do conserve them when they discuss them. For a brief overview, see Jeffrey Pfeffer, New Directions for Organization Theory: Problems and Prospects (New York: Oxford Univ. Pr., 1997), 75-77.

18. Only a few cost-per-use studies have identified this differential; at Albany-SUNY, it was tenfold for the sciences (Gossen and Irving, "Ownership versus Access," 46); at Columbia University, it was eighteenfold, a figure actually deflated by a very high document delivery estimate in the early 1990s of \$39 (Ferguson and Kehoe, "Access vs. Ownership," 94).

19. Sara Kiesler and Lee Sproull, "Managerial Response to Changing Environments: Perspectives on Problem Sensing from Social Cognition," Administrative Science Quarterly 27 Dec. 1982): 548-70. 


\title{
Commentaries on the New Model at Other Libraries
}

\begin{abstract}
No single study can be simultaneously accurate (scientific), general (theoretical), and simple (practical). To secure any two of these virtues automatically sacrifices the third one. The case study by Charles A. Schwartz on pages 115-124 of a new serials model is simple and accurate, thus its generality is inevitably doubtful. The following commentaries make the case study more general and accurate but less simple. Those are inevitable trade-offs.
\end{abstract}

\section{Colorado State University Joel Rutstein}

Colorado State University (CSO) had the original inspiration for what would become the UnCover SUMO (subsidized unmediated ordering) document delivery service. That formative idea was not the product of a declining economic situation but, rather, an improving one. After a $\$ 100,000$ serials cancellation project in 1992, we had an abundant materials budget that was ranked as the number one priority in the university's strategic plan. Why, then, did CSO propose in 1993 that the Colorado Association of Research Libraries invent SUMO? Simply, if the current situation is healthy, what better time to experiment?

Thus, SUMO developed out of a CSO pilot project to analyze behavioral patterns of library users in what would be a substantially new information environment. As pioneers in this area, we needed to discover how a cost-free document delivery service actually would be used, its financial ramifications for the library, its impact on interlibrary loan, and whether-despite being unmediated-it would require much staff intervention.
In 1994, CSO became the first library to offer UnCover SUMO. Undergraduates and residents of Fort Collins were included in the authorized-user pool. Two controls were placed on the service: All titles owned by the library, and articles costing more than $\$ 25$, were blocked from the subsidy. After the service had been in operation for two years (through 1996), the following conclusions were drawn about the nature of the service in CSO's environment:

- Interlibrary loan: There was no appreciable decline in demand, in that articles available through UnCover continue to be requested through ILL.

- Overall cost: From $\$ 28,700$ in FY1995, the cost rose to $\$ 40,900$ in FY1996 and might plateau at about $\$ 45,000$ in FY1997. One source of rising cost is copyright charges: They averaged $\$ 4.70$ in FY1995, \$5.74 in FY1996, and \$6.50 in FY1997. The average document delivery charge was about $\$ 13$ for FY1997. The other source of rising cost is spreading use of the service at CSO.

- Serial access frequency: Abouthalf (48\%) of all serials in CSO's document delivery experience involve one article only, whereas 15 percent involve five or more requests.

Joel S. Rutstein, formerly Collection Development Officer, is Coordinator of the Gifts Program in the William E. Morgan Library at Colorado State University; e-mail: jrutstein@manta.library.colostate.edu. 


\begin{tabular}{|lccl|}
\hline \multicolumn{4}{c|}{ TABLE 1 } \\
User-Group Behaviors \\
\hline & UnCover & UnCover \\
Group & Browsing & Orders & ILL \\
\hline Faculty & $10 \%$ & $19 \%$ & $30 \%$ \\
Staff & 6 & 7 & 10 \\
Grad students & 43 & 52 & 50 \\
Undergraduates & 41 & 22 & 10 \\
\hline
\end{tabular}

A key finding is the greater use of UnCover by students, for both browsing and ordering, than by the faculty, who generally are conservative about altering their research methods.

-Fill rate and delivery time: The fill rate was 87 percent, with the following delivery times: one hour, 17 percent; twenty-four hours, 44 percent; two days, 21 percent; longer

- Access-versus-ownership costs: Of the 15 percent of serials involving five or more requests, one in six had document delivery charges greater than their subscription costs (overall \$3,179 versus $\$ 1,896)$, the other five had access charges far lower than subscription costs (overall $\$ 14,062$ versus $\$ 126,597$ ); on balance, a savings of $\$ 109,000$.

\section{than two days, 18 percent.}

Overall, usage of the service reflects the library's collection development allocation formulae, which give the greatest weights to graduate student needs and next to faculty needs. Continuing analyses of UnCover will be integrated into the larger planning for electronic information access.

\section{University of Kansas Melvin G. DeSart and Rachel Miller}

The restructuring experience of the University of Kansas (KU) varies from that of UM-B in three respects: KU's serials review process was gradual and multiyear, as opposed to UM-B's all-atonce approach; KU's document delivery service was not implemented in concert with a particular serials review, whereas UM-B used the prospect of document delivery as a strategy with faculty; and the access-versus-ownership decision models differed.

Over the past ten years at KU, many high-cost, low-use serials were cut. In fact, KU's implementation of a customized UnCover SUMO system in 1995 was driven largely by the cumulative effect of such cancellation projects. Whereas
UM-B's UnCover system was part and parcel of a single, fairly comprehensive project, KU's UnCover implementation and subsequent serials restructuring were the main ingredients of a remedy for a long-term trend of diminishing serials ownership.

By 1995, when KU implemented its customized SUMO service, there simply were not enough high-cost, low-use titles remaining in the KU science and technology collections to merit conducting the type of cost-per-use study done at UM-B. Rather, in the next cancellation project (spring 1996), we chose to follow the so-called "LSU model" by asking each faculty member to provide the serials he or she needed on-site. That entire process, including cancellation decisions, took less than four months. The resulting science and technology serial cuts ranged from a few titles that

Melvin G. DeSart is Engineering Librarian and Coordinator of Science Collection Department in the Spahr Engineering Library at the University of Kansas; e-mail: desart@ukans.edu. Rachel Miller is Head of Retrieval Services in the Watson Library at the University of Kansas; e-mail: miller@ukans.edu 
had not been on any faculty member's list to those that appeared on several lists but were consistently low ranked. Estimated cost per use was another decision factor, particularly when similar titles were being compared, but the serials canceled ran the price gamut, from $\$ 50$ to more than $\$ 5,000$. In the decision-making process, we chose to place primary emphasis on faculty needs and local usage, within the inevitable limits of the materials budget.

Past and continuing serial cancellations (creating more access demand), combined with growing awareness of the document delivery service, have caused at least a doubling of its initial cost $(\$ 25,000)$ during the past two years. Yet, the projected $\$ 50,000$ to $\$ 60,000$ cost for FY1998-being just five to six percent of the $\$ 953,922$ in former ownership costs of the 2,854 serials which KU has canceled since FY1991-is a bargain, especially in terms of the access and service provided.

We would underscore a point Tony Schwartz mentions: that creating a holdings tape (for the system to block orders involving serials held on-site) is an important reason to understand all the work involved in establishing this new service model. Because UnCover matches only on an OCLC or an International Standard Serial Number, the serials department had to add ISSNs to many records and even, when it was necessary to force-match titles that did not have either a usable OCLC number or ISSN, to create a special field in the bibliographic record to contain UnCover's identifier. Overall, the holdings tape was a laborious problem that had to be resolved if the new service was to be as cost-effective as possible.

\section{New Jersey Institute of Technology James Robertson}

In early 1995, the New Jersey Institute of Technology (NJIT) library canceled 150 serials, all available through UnCover, for a savings of $\$ 100,000$. Most of the savings were put in a document delivery fund that would support not only users' unmediated orders but also a good deal of interlibrary loan (ILL) requests. Unlike UM-B, NJIT did not have serial-usage data to identify low-use, high-cost-peruse titles. Instead, the library relied on faculty members' own estimates (and biases).

Later that fall, NJIT launched its UnCover SUMO system. Unlike most other universities that offer this service, NJIT allows its undergraduates to use it. Moreover, NJIT may have been unique in initially offering the service without any restrictions (i.e., there was no blocking of articles costing over a certain amount, nor were the titles held on-site blocked). That decision reflected a dual concern for collecting realistic data on user needs while avoiding inappropriate restrictions based on assumptions.

Economic restrictions eventually proved necessary. Whereas in FY1996 direct orders by users were $\$ 21,777$ and ILL orders \$20,652, in FY1997 direct orders were about $\$ 42,000$ and ILL orders about $\$ 14,500$. When projections showed UnCover expenditures outrunning available funds, the library put a block on titles held on-site and on articles costing more than $\$ 30$. The library currently is working with UnCover to limit the total dollars each member of a user class may spend before one must apply to the library for a new account. (Possible limits

James Robertson is Director of the Architecture Library of the Robert W. Van Houton Library at the New Jersey Institute of Technology; e-mail: robertson@tesla.njit.edu. 
would be $\$ 300$ per undergraduate student, $\$ 500$ per staff member, and $\$ 1,000$ per graduate student or faculty member.) UnCover provides a SUMO library monthly computer disk report with details on every order (e.g., user name, date and time of order and delivery, cost and bibliographic information). Library staff integrate all reports into a cumulative Microsoft Access database.

Ideally, the UnCover system would allow the library to fine-tune the level of restrictions on individual users. The longterm solution is to reinstate the library in the order transaction-but as an automated process, rather than a manual one. The NJIT library has proposed developing computer middleware (software) which would reside on campus. Users would go through the middleware to access UnCover. When a user submits an order, the middleware would first check its files for restrictions, such as the user's cumulative cost over a given time period, the cost of each article, whether the serials involved are held on-site, and whether there was a duplicate order for that user.
If the middleware authorizes the order, it would pass the order to UnCover and update the customer's local order history file. This interaction would be transparent to the user.

The middleware would be an improvement over the current system in two ways: It would allow sophisticated, multivariate automated mediation; and it would enable the library staff to quickly monitor economic transactions and user behavior. Further, the middleware conceivably could be developed to work with other document delivery vendors. Users would neither know nor care whether the requested article came from UnCover or, for example, UMI, CISTI, or IEEE. The middleware would make an automated decision based on cost efficiency and user satisfaction criteria. The NJIT library believes this is an important future direction in library service and invites collaboration with libraries and vendors interested in such middleware. Further information on the NJIT library's UnCover project is updated periodically on the library's Web site at: http:/ / www.njit.edu/njIT/Library/uncover/report.html. 